\title{
Predicting fish weight using photographic image analysis: a case study of broad whitefish in the lower Mackenzie River watershed
}

\author{
Sarah B. Gutzmann (10), Emma E. Hodgson ${ }^{a}$, Douglas Braun ${ }^{b}$, Jonathan W. Moore ${ }^{a}$, and Rachel A. Hovel (i) \\ ${ }^{a}$ Department of Biological Sciences, Simon Fraser University, 8888 University Drive, Burnaby, BC V5A 1S6, Canada; ${ }^{b}$ Freshwater \\ Ecosystems, Fisheries and Oceans Canada, Simon Fraser University, 8888 University Drive, Burnaby, BC V5A 1S6, Canada; \\ ${ }^{c}$ Department of Biology, University of Maine at Farmington, 173 High Street, Farmington, ME 04938, USA
}

Corresponding author: Emma E. Hodgson (email: emma.hodgson@dfo-mpo.gc.ca)

\begin{abstract}
Many small-scale fisheries are remote in nature, making data collection logistically difficult. Thus, there is a need for accessible solutions that address the data gaps present in these fisheries. One possible solution is to incorporate photography into community- or harvest-based monitoring frameworks and employ these images to estimate biological data. Here, we test this approach using tuk dagaii, or broad whitefish, Coregonus nasus (Pallus, 1776) in the Gwich'in Settlement Area, a remote region in the Mackenzie River system in Canada's Northwest Territories. We used photographs taken by Gwich'in collaborators using a simple, standardized set-up to ask the question: how accurately can weight be estimated from a photo? Using random forest models based on morphometric photograph measurements as well as season and location of harvest, we predicted broad whitefish weight to within $13 \%$ of true weight $(257 \mathrm{~g}$, for fish weighing an average of $2036 \mathrm{~g})$. The model predictions were well distributed in their residuals for most fish, though we discuss biases at low and high weights. Image analysis is a simple, low cost, and accessible method that may contribute to ongoing, community/harvest-based fishery data collection where fish length (measured) and weight (predicted) can be tracked through time.
\end{abstract}

Key words: image analysis, community-based monitoring, broad whitefish, random forest analysis, fisheries monitoring

\section{Résumé}

De nombreuses petites pêcheries sont éloignées dans la nature, ce qui rend la collecte de données difficile sur le plan logistique. Il est donc nécessaire de trouver des solutions accessibles pour combler le manque de données dans ces pêcheries. Une solution possible est d'intégrer la photographie dans les cadres de surveillance fondés sur la communauté ou sur la récolte et d'utiliser ces images pour estimer des données biologiques. Les auteurs testent ici cette approche en utilisant le łuk dagaii, ou corégone tschir, Coregonus nasus (Pallus, 1776), dans la zone d'établissement des Gwich'in, une région éloignée du système du fleuve Mackenzie dans les Territoires du Nord-Ouest au Canada. Ils ont utilisé des photographies prises par des collaborateurs Gwich'in à l'aide d'une installation simple et standardisée pour poser la question suivante : avec quelle précision peut-on estimer le poids à partir d'une photo? En utilisant des modèles forestiers aléatoires fondés sur les mesures de photographies morphométriques ainsi que sur la saison et le lieu de récolte, ils ont prédit le poids du corégone à $13 \%$ près du poids réel (257 $\mathrm{g}$, pour des poissons pesant en moyenne $2036 \mathrm{~g}$ ). Les prédictions du modèle étaient bien distribuées dans leurs résidus pour la plupart des poissons, mais les auteurs abordent la question des biais pour les poids faibles et élevés. L'analyse d'images est une méthode simple, peu coûteuse et accessible qui peut contribuer à la collecte continue de données de pêcheries fondées sur la communauté ou sur la récolte où la longueur (mesurée) et le poids (prédit) des poissons peuvent être suivis dans le temps. [Traduit par la Rédaction]

Mots-clés : analyse d'image, surveillance fondée sur la communauté, corégone tschir, analyse forestière aléatoire, surveillance des pêches

\section{Introduction}

Collecting fisheries data can be difficult for small-scale fisheries in remote regions because of financial and logistical constraints. For instance, in northern Canada, there has been very limited effort to document small-scale fishery catches (Zeller et al. 2011); yet, it is a system where basic biological data are considerably lacking for many species (Dey et al. 2018). One method of collecting data in these situations 
is harvest- or community-based monitoring, where trained fishers gather information (e.g., record measurements) from their catch, creating the opportunity for long-term biological data sets while a species is harvested, often for subsistence (Bell and Harwood 2012).

Innovative and accessible solutions that are suitable for widespread use could address some of the data gaps present in small-scale fisheries (Pita et al. 2019), and technology is becoming increasingly available to do so (Bradley et al. 2019). For example, cameras have been trialed in small-scale fisheries to identify species (Bartholomew et al. 2018), to monitor regulation compliance (Pitcher et al. 2009), and as a means for trained community members to report shark landings (Jeffers et al. 2019). Image analysis has also been used to discern fish morphometrics in large-scale fishing and aquaculture industries (Balaban et al. 2010).

Here, we investigated the potential application of data collection through photography and image analysis for a tuk dagaii or broad whitefish (Coregonus nasus (Pallus, 1776)) fishery in the Gwich'in Settlement Area (GSA) in the western Canadian Arctic (Fig. 1). To evaluate an accessible data collection tool that could be utilized by a community-based monitoring program, we explored the feasibility of predicting broad whitefish weight from fish measurements (e.g., length) derived from photographs. Monitoring fish weight is of interest because from fish length and weight one can understand fish body condition, and potentially fecundity, where changes in these characteristics through time can indicate stress on a population (Pope et al. 2010). In the GSA, healthy, robust fish populations are intertwined with the well-being of Gwich'in peoples as fishing is integral to Gwich'in identity and culture (Proverbs 2019) and provides an important source of recreation and food (Kuhnlein et al. 2009). Moreover, fish weight is directly related to the amount of food obtained from a fishery. Using the methods presented herein, fisheries data could be collected through the ongoing submission and measurement of appropriately collected photographs of broad whitefish harvested for subsistence. Hence, these methods can allow for long-term data collection that is not constrained to a field season, schedule, or budget.

We used random forest (RF) analysis in a model selection process to discern prediction accuracy and which set of measurements best predicted broad whitefish weight. Specifically, we addressed the question: how accurately can weight be estimated from a photo? To do this, we investigated (1) what was the best set of morphometric measurements to predict fish weight without any additional knowledge (such as location or season of capture)? and (2) when location and season of capture are known, do these variables improve predictive ability?

\section{Methods}

\section{Study system}

This study was a part of a research program that began in 2017 between Gwich'in community members, renewable resources organizations within the GSA, and university scientists (Hovel et al. 2020). The monitoring and sample collec- tion of broad whitefish (herein, whitefish as is the common name in the GSA) used in this study was done by Gwich'in community collaborators (herein, monitors) (Hodgson et al. 2020). As part of the ongoing collaborative structure of this research, the results from this study were shared with the three Gwich'in communities involved in the monitoring program through a plain language summary and community presentations.

The Mackenzie River ends in the largest Arctic delta in North America (Burn and Kokelj 2009). In this region, whitefish have diverse life-history strategies (Harris et al. 2012a) with at least four described migratory patterns (Harris et al. 2012b). While whitefish are not considered to be under immediate threat (Committee on the Status of Endangered Wildlife in Canada 2019), this species is susceptible to the impacts of a changing environment as it inhabits one of the most rapidly warming areas on the planet (Bush and Lemmen 2019). Whitefish have been harvested since time immemorial by Gwich'in peoples in the lower Mackenzie River watershed (Thompson and Millar 2007). Fishing occurs on the lower Mackenzie River (Nagwichoonjik), Artic Red River (Tsiigehnjik), and Peel River (Teetł'it Gwinjik) (Gwich'in Social and Cultural Institute 2016).

\section{Data collection}

Community monitors collected photographs of fish captured as part of the subsistence fishery along the Peel Channel in the Mackenzie Delta and the Peel River (Fig. S1) between July and October in 2017 and 2018. Thus, this study utilized opportunistic sampling of fish that were being harvested already. Fish were caught in gillnets (5-25 $\mathrm{m}$ in length; $\sim 10$ or $13 \mathrm{~cm}$ mesh size). Monitors measured fish length (using a measuring tape) and weight (using a Brecknell ElectroSamson digital hanging scale, $10.00 \pm 0.01 \mathrm{~kg}$ ), and took a photograph (using a Nikon COOLPIX W100 13.2MP waterproof digital camera). Photographs were taken from directly above and included the entire fish. At the start of each season, monitors were trained in all fish measurement methods, including how to photograph the fish consistently. Photograph methods included ensuring that the fish was laid straight and flat, and the entire body was in the image (Fig. 1). The photograph set-up was intentionally kept simple (e.g., no copy stand was used) to increase accessibility among users. Research was conducted under Aurora Research Institute Scientific Research License No. 16225, Simon Fraser University Animal Care Protocol \#1248B-17, and Fisheries and Oceans Canada (DFO) permit DFO LFSP S-18/19 3015-YK.

We used Image (Schindelin et al. 2012) to take 15 measurements from each photograph. Measurements were selected based on (1) a modified Truss measurement method (Strauss and Bookstein 1982; modified based on Beddow and Ross 1996 and Hockaday et al. 2000) giving lines 1-2, 1-3, 1-4, 2-3, $2-4,3-4,3-5,3-6,4-5,4-6$, and 5-6; (2) traditional methods of predicting weight from fish length and body depth (as in Jones, Petrell and Pauly 1999) giving lines A-F and 3-E; and (3) monitor knowledge identifying differing belly size between fish, which is captured in the region of the body measured by lines 3-D and B-C (Fig. 1; see Fig. S2 for details). 
Fig. 1. Top left: all 15 photograph measurements where bold lines indicate measurements used in weight-IV-SL (see Fig. S2 for details on measurement landmarks). Top right: location in Canada of the Gwich'in Settlement Area. Bottom: weight-IV-SL true versus predicted broad whitefish weights (see Results section for more details). Dashed black line is the 1:1 line. Black, solid line is the trendline of the plotted testing data. Grey shaded area is $95 \%$ confidence interval. Tick marks denote the distribution of the training data true weights.

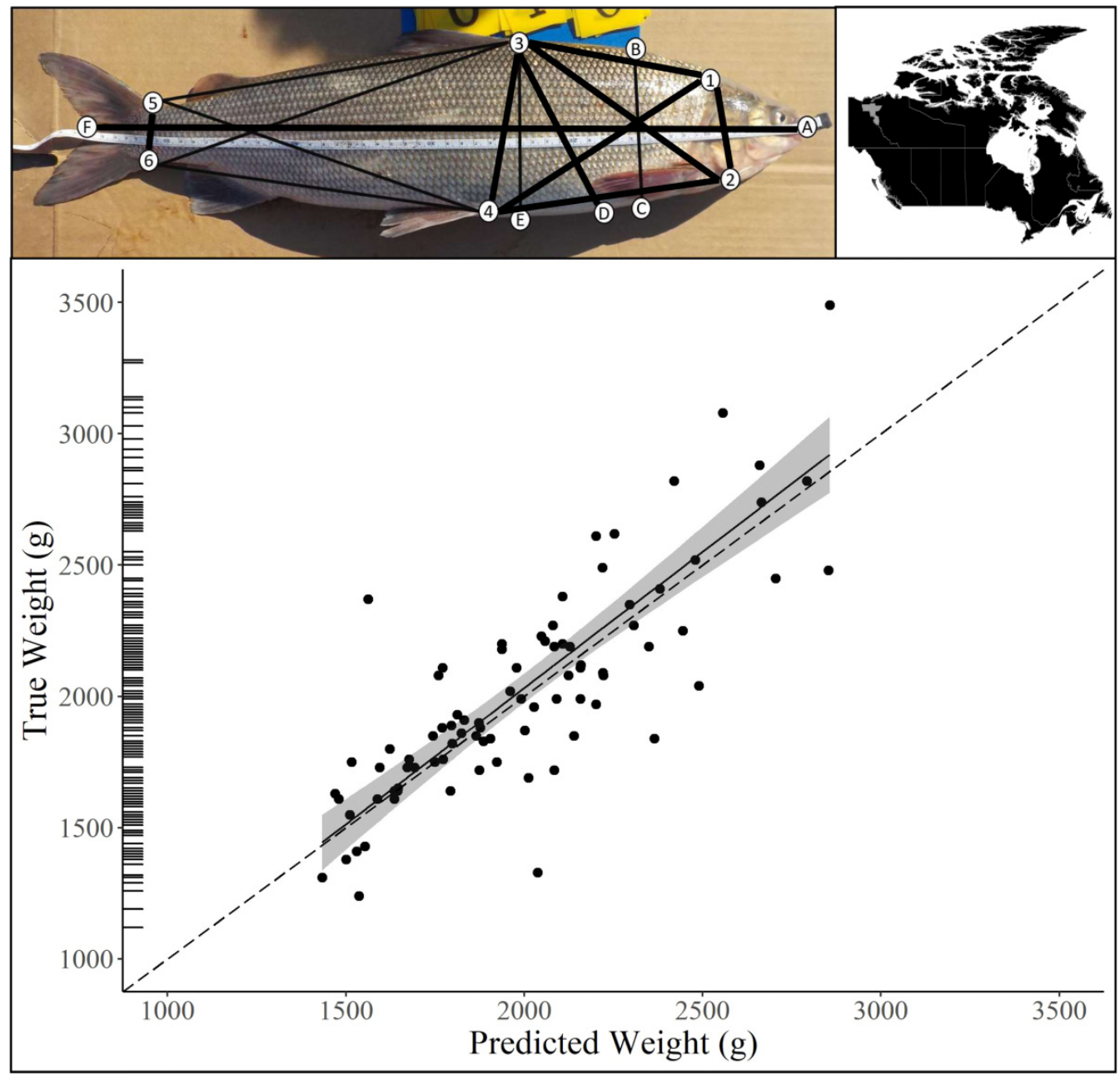

Photograph analysis includes measurement error. Inherent to the act of photography, the conversion of a 3D item into a 2D image may distort distances, making photographbased measurements shorter than they would be on the real fish (Petrtýl et al. 2014). Error due to different operators is also possible (Fruciano 2016). We took steps to mitigate both sources of error and provide the details in Section S1 (error mitigation) in the Supplementary material.

In addition to the photograph measurements, the categorical variables of location ("Peel” or "delta") and time of harvest (July, August, or September/October (which were combined due to the small sample size in October), herein collectively referred to as season) were included in our analysis to explore whether additional variation in weight could be explained. Sample location was used as a categorical variable because there is preliminary evidence that Peel River and Mackenzie Delta whitefish differ in weight (R. Hovel, J. Moore, E. Hodgson, and T. Lantz, personal communication, 2019). Season was used due to the potential for seasonal shifts in body shape due to environmental or life-history factors. For example, female fish become increasingly gravid in the fall. We hypothesized that body size characteristics may change accordingly as eggs develop; however, fish sex was not differentiated as gonads were not checked for all fish in our data set. We explored time through the season rather than between years as we expected sizes to change from the beginning to end of summer but did not hypothesize that they would change substantially between years.

\section{RF analysis}

We used RF analysis to explore model predictions for whitefish weight. RFs are collections of decision trees where data are split into nonoverlapping categories by randomly sampling with replacement of two-thirds of the data (Liaw and Wiener 2002). RFs decorrelate their generated trees by randomly selecting a subset of all explanatory variables to consider at each split in the tree (Liaw and Wiener 2002). We generated RFs with the randomForest package (Liaw and Wiener 
2002) in $\mathrm{R}$ (version 3.6.2; R Core Team 2019), retaining the default setting for the number of parameters (one-third) at each split (Liaw and Wiener 2002), but increasing the total number of trees in each model from default (500) to 100000 (see Section 2 in the Supplementary material for RF rationale, including number of trees (Figs. S3-S8) and in comparison to linear models).

We split the full suite of data (281 fish) into two subsets: training and testing. The training subset was composed of 196 randomly selected fish (70\% of the data) and was used to develop the prediction models. The testing subset consisted of the remaining 85 fish and was used for cross-validation (for details on data distribution, see Table S1).

In total, we tested 20 models to predict weight using a twophased approach to investigate (1) what was the best set of morphometric measurements to predict fish weight and (2) whether including location and season as variables improved predictive ability. In the first phase, we selected suites of measurements to make five models. The first model was the most complex (weight-I; all 15 measurements). In the next three models, we dropped the most correlated variables (correlation $>0.9$ ) as a model with fewer measurements would streamline the measurement process (weight-II $=10$ measurements, weight-III $=9$ measurements, and weight-IV $=9$ measurements; Table S2). The final model, weight-V, used only one measurement to predict weight (A-F; length), based on traditional approaches (Spencer 1898 as referenced in Beddow and Ross 1996). In phase 2 , the location and (or) season were added to each of the five phase 1 models (represented in the model name by "L" or "S", respectively) to see whether these parameters improved predictive accuracy. This created an additional 15 models (Table S2).

We identified the most statistically accurate model using the root mean squared error (RMSE) rounded to the nearest gram. When RMSE was the same, we used the intercept and slope of the "true weight" versus "predicted weight" (TP) regression line (Table S2). It was expected that the most accurate model would have the RMSE and TP intercept closest to 0 , and TP slope closest to 1 .

\section{Results}

The training and testing data (196 and 85 fish, respectively) both had similar characteristics (Fig. S9). Training data whitefish photo length (A-F) ranged from 398 to $606 \mathrm{~mm}$ (mean $=482 \mathrm{~mm}$ ) and testing data fish length ranged from 392 to $615 \mathrm{~mm}$ (mean $=483 \mathrm{~mm}$ ). Whitefish true weights ranged from 1120 to $3280 \mathrm{~g}$ (mean $=2038 \mathrm{~g}$ ) in the training data and from 1240 to $3820 \mathrm{~g}$ (mean $=2036 \mathrm{~g}$ ) in the testing data.

Photograph measures of fish length and body size contributed to the best prediction of weight (models weightI through weight-IV) over a length-only model (weight-V). Based on performance metrics for accuracy and bias, weightIV (measurements A-F, 1-2, 1-3, 1-4, 2-3, 2-4, 3-4, 56 , and D-3) was selected as the best model from phase $1(\mathrm{RMSE}=260 \mathrm{~g}$, TP intercept $=-31 \mathrm{~g}$, and TP slope $=1.03$; Table S2). Comparatively, weight-V performed the worst $(\mathrm{RMSE}=358 \mathrm{~g}, \mathrm{TP}=534 \mathrm{~g}$, and TP slope $=0.74$; Table S2).
In phase 2, season and sampling location improved model predictions. Weight-IV-SL was the best phase 2 model $(\mathrm{RMSE}=257 \mathrm{~g}$, TP intercept $=-43 \mathrm{~g}$, and TP slope $=1.04$; Table S2), and had the lowest RMSE out of both phases; therefore, it was selected as the best model overall (weight-IV-SL also predicts whitefish weight more accurately than a simple linear model; see Section S3 (linear model) and Fig. S10 in the Supplementary material). Comparing the true weights of test data whitefish with their predicted weights (Fig. 1), weight-IVSL predicted within $13.22 \%$ of true fish weight on average.

Weight-IV-SL performed consistently for the majority of fish sizes evaluated. We assessed model bias using residual density (Fig. S11) and by comparing residuals to predicted (Fig. S12) and true (Fig. S13) fish weight. We note that, when plotted against true weight, there is a bias in model predictions where the weight of lighter fish is overestimated and that of heavier fish is underestimated; this is discussed further below.

\section{Discussion}

We found that whitefish weight can be estimated from photographs using morphometric measurements paired with information on sampling location and season of capture. For an average whitefish that weighed $2036 \mathrm{~g}$, the selected model (weight-IV-SL) predicted weight within an average of $257 \mathrm{~g}$ (13.22\% different) from true weight. While the best model included measurements, season, and location of capture, similar RMSE values show that a measurement-only model may perform sufficiently well (i.e., weight-IV; RMSE $=260 \mathrm{~g}$; $13.38 \%$ different) in cases where a simpler approach is of value (e.g., when season and location are not recorded, the model could still be applied). This research suggests that photography and image analysis provide an opportunity for collection and verification of basic biological data in remote regions that may be data poor.

This study aimed to test methods that would be accessible to community-based monitoring programs in remote regions. Community- or volunteer-based projects have been shown to be valuable sources of data (Pattengill-Semmens and Semmens 2003). In this case, fish length (measured) and weight (predicted) could be used to track changes in these parameters as well as fish condition through time, where photographs of both future and historical catches can be analyzed. Gwich'in monitors took photographs using a simple set-up, and all computation was done using free software. Photograph-based methods such as these may help avoid the need to distribute multiple pieces of potentially expensive and (or) cumbersome equipment to participants and reduce in-field time requirements. Moreover, a photographic record could be used for other applications such as checking for/documenting external parasites or lesions, which can indict stress on a population (Pope et al. 2010).

A remaining challenge from this study is that weights were overestimated for light fish and underestimated for heavy fish (Fig. 1; Figs. S12 and S13). Because RFs predict new observations using the averages of a known data set, these two trends may in part be due to limited data at the extremes of observed fish size (see Section S4 in Supplementary material 
(limited data) for details). Regardless, there are inherent limitations of measuring a laterally oriented photograph. For example, if weight is at some point accumulated (or lost) not in lateral body size (e.g., length or depth) but in girth, it would not be captured in a photograph. This is consistent with our findings in that weight-IV-SL was not biased for the majority of whitefish conditions but tended to overpredict at the low and high extremes (Fig. S14). For this, further work would benefit from testing the addition of a photograph and corresponding measurement(s) of the ventral side of each fish. Future work may also investigate alternative measures of size to predict weight (e.g., centroid size or lateral area) and (or) ways to automate the prediction process through mobile computation (e.g., a smart phone application; Bradley et al. 2019). Finally, should this approach be implemented, it could benefit from exploring a bias correction approach for those heavier and lighter weight fish.

Globally, there is a need to improve small-scale fisheries management. The data-poor nature of these fisheries can severely impact the food security, culture, and economies of the communities that depend on them (Chuenpagdee et al. 2019). Accessible solutions are needed to tackle these complex systems, particularly in remote regions like the GSA. Whitefish are a priority for monitoring as they are the most important fish to Gwich'in communities in Canada and inhabit a region of the Arctic that is rapidly changing. New technologies like camera-based monitoring are becoming increasingly available to fill data gaps (Bradley et al. 2019), and the tool presented here to estimate whitefish weight from a photograph advances one accessible method of remote fisheries data collection.

\section{Acknowledgements}

Mashi'cho, thank you, to community monitors Alice and Ernest Vittrekwa, Abe Stewart, Mary Effie Snowshoe, Louie Cardinal, and Wally Tyrell; research assistants William Tyrell, Richard Stewart, Rayna Vittrekwa, and Arlyn Charlie; and Gwich'in Renewable Resources Board members Amy Amos, Janet Boxwell, and Sarah Lord; and to the Northwest Territories Cumulative Impact Monitoring Program, TrackingChange, and the Gwich'in Renewable Resources Board for their integral roles in the harvest-based monitoring study that made this project possible. We also thank our two anonymous reviewers for their valuable feedback. This research was supported by Northwest Territories Cumulative Impacts Monitoring Program (grant No. 195), Gwich'in Renewable Resources Board Youth Engagement Fund, and Liber Ero Postdoctoral Fellowship.

\section{Article information}

\section{History dates}

Received: 13 April 2021

Accepted: 23 December 2021

Accepted manuscript online: 3 March 2022

Version of record online: 30 August 2022

\section{Copyright}

(C) 2022 Authors Gutzmann, Moore, and Hovel, and The Crown. This work is licensed under a Creative Commons Attribution 4.0 International License (CC BY 4.0), which permits unrestricted use, distribution, and reproduction in any medium, provided the original author(s) and source are credited.

\section{Data availability}

All data used in this manuscript are available through Zenodo, doi:10.5281/zenodo.4677774.

\section{Author information}

\section{Author ORCIDs}

Sarah B. Gutzmann https://orcid.org/0000-0003-4688-3569

Rachel A. Hovel https://orcid.org/0000-0002-3452-9485

\section{Author notes}

Present address for Emma E. Hodgson is Freshwater Ecosystems, Fisheries and Oceans Canada, 4222 Columbia Valley Highway, Cultus Lake, BC V2R 5B6, Canada

\section{Competing interests}

The authors declare there are no competing interests.

\section{Supplementary material}

Supplementary data are available with the article at https: //doi.org/10.1139/AS-2021-0017.

\section{References}

Balaban, M.O., Şengör, G.F.U., Soriano, M.G., and Ruiz, E.G. 2010. Using image analysis to predict the weight of Alaskan salmon of different species. Journal of Food Science, 75(3): E157-E162. doi:10.1111/ j.1750-3841.2010.01522.x.

Bartholomew, D.C., Mangel, J.C., Alfaro-Shigueto, J., Pingo, S., Jimenez, A., and Godley, B.J. 2018. Remote electronic monitoring as a potential alternative to on-board observers in small-scale fisheries. Biological Conservation, 219: 35-45. doi:10.1016/j.biocon.2018.01.003.

Beddow, T.A., and Ross, L.G. 1996. Predicting biomass of Atlantic salmon from morphometric lateral measurements. Journal of Fish Biology, 49(3): 469-482. doi:10.1006/jfbi.1996.0173.

Bell, R.K., and Harwood, L.A. 2012. Harvest-based monitoring in the Inuvialuit Settlement Region: steps for success. Arctic, 65(4): 421-432. doi:10.14430/arctic4240.

Bradley, D., Merrifield, M., Miller, K.M., Lomonico, S., Wilson, J.R., and Gleason, M.G. 2019. Opportunities to improve fisheries management through innovative technology and advanced data systems. Fish and Fisheries, 20(3): 564-583. doi:10.1111/faf.12361.

Burn, C.R., and Kokelj, S.V. 2009. The environment and permafrost of the Mackenzie Delta area. Permafrost and Periglacial Processes, 20(2): 83105. doi:10.1002/ppp.655.

Bush, E., and Lemmen, D.S. 2019. Canada's changing climate report. Government of Canada, Ottawa, ON.

Chuenpagdee, R., Rocklin, D., Bishop, D., Hynes, M., Greene, R., Lorenzi, M.R., and Devillers, R. 2019. The global information system on smallscale fisheries (ISSF): a crowdsourced knowledge platform. Marine Policy, 101(2017): 158-166. doi:10.1016/j.marpol.2017.06.018.

Committee on the Status of Endangered Wildlife in Canada. 2019. COSEWIC candidate wildlife species. Available from https://www.co sewic.ca/index.php/en-ca/reports/candidate-wildlife-species.html [accessed 26 March 2019]. 
Dey, C.J., Yurkowski, D.J., Schuster, R., Shiffman, D.S., and Bittick, S.J. 2018. Patterns of uncertainty in life-history and extinction risk for Arctic vertebrates. Arctic Science, 4(4): 710-721. doi:10.1139/ as-2018-0006.

Fruciano, C. 2016. Measurement error in geometric morphometrics. Development Genes and Evolution, 226(3): 139-158. doi:10.1007| s00427-016-0537-4. PMID: 27038025.

Gwich'in Social and Cultural Institute. 2016. About the Gwich'in. Available from https://gwichin.ca/. [accessed October 2018].

Harris, L.N., Taylor, E.B., Tallman, R.F., and Reist, J.D. 2012a. Gene flow and effective population size in two life-history types of broad whitefish Coregonus nasus from the Canadian Arctic. Journal of Fish Biology, 81(1): 288-307. doi:10.1111/j.1095-8649.2012.03339.x. PMID: 22747819.

Harris, L.N., Loewen, T.N., Reist, J.D., Halden, N.M., Babaluk, J.A., and Tallman, R.F. 2012b. Migratory variation in Mackenzie River system broad whitefish: insights from otolith strontium distributions. Transactions of the American Fisheries Society, 141(6): 1574-1585. doi:10.1080/00028487.2012.713885.

Hockaday, S., Beddow, T.A., Stone, M., Hancock, P., and Ross, L.G. 2000 Using truss networks to estimate the biomass of Oreochromis niloticus, and to investigate shape characteristics. Journal of Fish Biology, 57(4): 981-1000. doi:10.1006/jfbi.2000.1362.

Hodgson, E.E., Hovel, R.A., Ward, E.J., Lord, S., and Moore, J.W. 2020. Migratory diversity in an Arctic fish supporting subsistence harvest. Biological Conservation, 248(June): 108685. doi:10.1016/j.biocon.2020. 108685.

Hovel, R.A., Brammer, J.R., Hodgson, E.E., Amos, A., Lantz, T.C., Turner, C., et al. 2020. The importance of continuous dialogue in communitybased wildlife monitoring: case studies of dzan and tuk dagaii in the Gwich'in settlement area. Arctic Science, 6(3): 154-172. doi:10.1139/ as-2019-0012.

Jeffers, V.F., Humber, F., Nohasiarivelo, T., Botosoamananto, R., and Anderson, L.G. 2019. Trialling the use of smartphones as a tool to address gaps in small-scale fisheries catch data in southwest Madagascar. Marine Policy, 99(2019): 267-274. doi:10.1016/j.marpol.2018.10.040.

Jones, R.E., Petrell, R.J., and Pauly, D. 1999. Using modified length-weight relationships to assess the condition of fish. Aquacultural Engineering, 20(4): 261-276. doi:10.1016/S0144-8609(99)00020-5.

Kuhnlein, H.V., et al. 2009. Gwich'in traditional food for health: phase 1. In Indigenous peoples' food systems. Food and Agriculture Organization of the United Nations Centre for Indigenous Peoples' Nutrition and Environment, Rome, Italy. pp. 45-58. Available from https: //www.fao.org/3/i0370e/i0370e04.pdf [accessed 4 April 2019].
Liaw, A., and Wiener, M. 2002. Classification and regression by randomForest. R News, 2/3: 18-22. doi:10.1177/154405910408300516.

Pattengill-Semmens, C.V., and Semmens, B.X. 2003. Conservation and management applications of the REEF volunteer fish monitoring program. Environmental Monitoring and Assessment, 81(1-3): 43-50. doi:10.1023/A:1021300302208. PMID: 12620003.

Petrtýl, M., Kalous, L., and Memiş, D. 2014. Comparison of manual measurements and computer-assisted image analysis in fish morphometry. Turkish Journal of Veterinary and Animal Sciences, 38(1): 88-94. doi:10.3906/vet-1209-9.

Pita, C., Villasante, S., and Pascual-Fernández, J.J. 2019. Managing smallscale fisheries under data poor scenarios: lessons from around the world. Marine Policy, 101: 154-157. doi:10.1016/j.marpol.2019.02. 008.

Pitcher, T., Kalikoski, D., Pramod, G., and Short, K. 2009. Not honouring the code. Nature, 457: 658-659. doi:10.1038/457658a. PMID: 19194431.

Pope, K.L., Lochmann, S.E., and Young, M.K. 2010. Methods for assessing fish populations. Nebraska Cooperative Fish \& Wildlife Research Unit-Staff Publications, 73. p. 28. Available from http://digitalcom mons.unl.edu/ncf wrustaff/73 [accessed 4 April 2019].

Proverbs, T.A. 2019. Social-ecological change in Gwich'n territory: cumulative impacts in the cultural landscape, and determinants of access to fish. Master's thesis. University of Victoria, Victoria, BC, Canada.

R Core Team. 2019. R: a language and environment for statistical computing. R Foundation for Statistical Computing, Vienna, Austria. Available from https://www.r-project.org/.

Schindelin, J., Arganda-Carreras, I., Frise, E., Kaynig, V., Longair, M., Pietzsch, T., et al. 2012. Fiji: an open-source platform for biological-image analysis. Nature Methods, 9(7): 676-682. doi:10.1038/nmeth.2019. PMID: 22743772.

Strauss, R.E., and Bookstein, F.L. 1982. The truss: body form reconstructions in morphometrics. Systematic Biology, 31(2): 113-135. doi:10. 1093/sysbio/31.2.113.

Thompson, A., and Millar, N. 2007. Traditional knowledge of fish migration and spawning patterns in Tsiigehnjik (Arctic Red River) and Nagwichoonjik (Mackenzie River). Gwich'in Renewable Resource Board Report 07-01, Northwest Territories, Canada.

Zeller, D., Booth, S., Pakhomov, E., Swartz, W., and Pauly, D. 2011. Arctic fisheries catches in Russia, USA, and Canada: baselines for neglected ecosystems. Polar Biology, 34(7): 955-973. doi:10.1007| s00300-010-0952-3. 